\section{An Mspl RFLP detected by the human glandular kallikrein gene (hGK) on chromosome 19q}

\author{
R.Hermens, M.Coerwinkel, J.Trapman', \\ P.H.J.Riegman ${ }^{1}$, R.J.Vlietstra ${ }^{1}$, H.Smeets and \\ B.Wieringa \\ Department of Human Genetics, University of \\ Nijmegen, PO Box 9101, 6500 HB Nijmegen \\ and ${ }^{1}$ Department of Pathology, Erasmus \\ University, PO Box 1738, 3000 DR Rotterdam, \\ The Netherlands
}

Source/Description: A $1.5 \mathrm{~kb}$ hGK-cDNA segment cloned in the EcoRI site of pUC9.

Polymorphism: MspI (CCGG) detects a two allele polymorphism with bands at either $2.0 \mathrm{~kb}$ or $1.8 \mathrm{~kb}$. Faint constant bands light up at $2.4 \mathrm{~kb}, 1 \mathrm{~kb}$ and $0.8 \mathrm{~kb}$. Not polymorphic for TaqI and PstI, when tested on chromosomal DNA of ten unrelated individuals.

Frequency: Studied in 60 unrelated Caucasians: $2 \mathrm{~kb}$ allele (A1) 0.2 and $1.8 \mathrm{~kb}$ allele (A2) 0.8 .

Chromosomal Localisation: Localised at 19q13.2-qter by Southern blot analysis using a panel of human-rodent somatic cell hybrids containing unique segments of 19q (Schonk et al. 1989).

Mendelian Inheritance: Co-dominant segregation demonstrated in 8 myotonic dystrophy families.

Probe Availability: Contact P. Riegman.

Reference: Schonk et al. (1989) Genomics 4, 384-396.

Acknowledgements: This work was supported by the Dutch Praeventiefonds, grant $28-1165$, by grant Ro $389 / 15-2$ to H.H.Ropers from the Deutsche Forschungsgemeinschaft, by the Prinses Beatrixfonds, grant 87-2694, by the American Muscular Dystrophy Association and the Dutch Cancer Society (KWF).

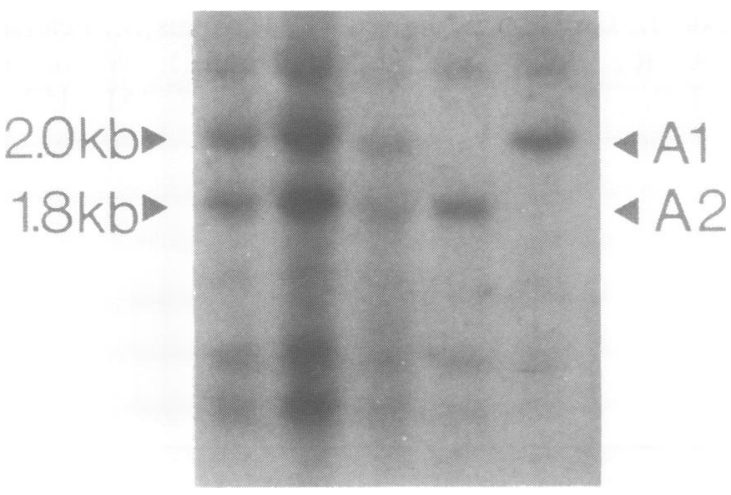

\section{Styl RFLP of the human platelet derived growth factor (PDGF) A-chain gene}

\section{G.A.A.Ferns and R.Ross}

Department of Pathology, School of Medicine SM-30, University of Washington, Seattle, WA 98195, USA

Source and Description of Clone: A human $1.3 \mathrm{kbp}$ cDNA fragment (clone D1) spanning exons 1 to 7 of the PDGF A-chain gene and including some of the flanking regions (1).

Polymorphism: StyI digestion reveals multiple alleles ranging from 1.1 to approximately $1.7 \mathrm{kbp}$ in size.

Frequency: The heterozygosity rate in $\mathbf{4 0}$ unrelated Caucasian subjects was $40 \%(16 / 40)$.

Not Polymorphic For: BamH I, Bgl I, EcoR I, Sst I and Xba $I$ in twelve individuals.

Chromosomal Localisation: Long arm of chromosome 7. 7q11.23 (2).

Mendelian Inheritance: Co-dominant inheritance in one family.

Probe Availability: Contact C-H Heldin, Ludwig Institute, Biomedicum 5-751 23 Uppsala, Sweden.

Other Comments: Best visualized by separating fragments on a $0.85 \%$ agarose gel at $1.5 \mathrm{~V} / \mathrm{cm}$ for 20 hours.

References: 1. Betsholtz,C. et al. (1986) Nature 320, 695-699, 2. Stenman et al. (1988) Exp. Cell Res. 178, 180-184.

Acknowledgements: This work was supported by grants from the NIH (HL-18645) and the British Heart Foundation. GAAF is a British Heart Foundation-American Heart Association Fellow.
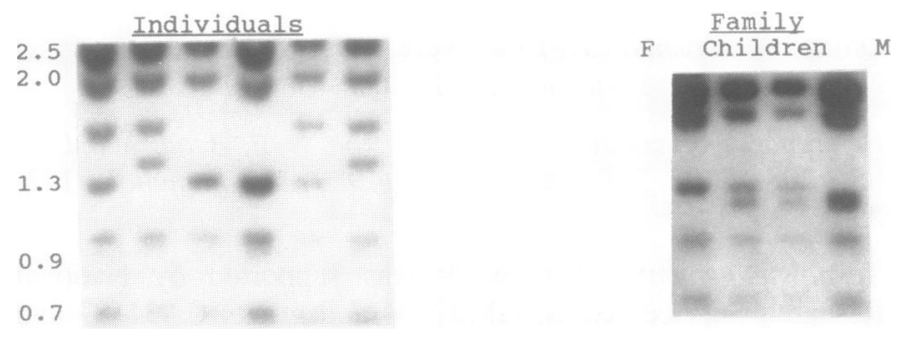